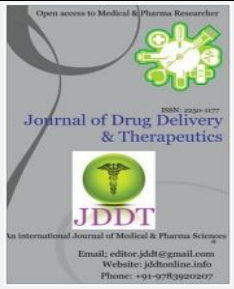

Open $\bigcirc$ Access

Research Article

\title{
SYNTHESIS AND COMPARISON OF PEG-IBUPROFEN AND PEG- KETOPROFEN PRODRUGS BY IN VITRO AND IN VIVO EVALUATION
}

\author{
Durgaprasad Kemisetti* ${ }^{1}$ and Sarangapani Manda ${ }^{2}$ \\ ${ }^{1}$ Associate Professor, Department of Pharmaceutical Chemistry, Vaagdevi Pharmacy College, Bollikunta, Warangal-506005, India \\ ${ }^{2}$ Dean and Professor, Department of Pharmaceutical Chemistry, University College of Pharmaceutical Sciences, Kakatiya \\ University, Warangal-506009, India
}

\begin{abstract}
Pain is an unpleasant sensation experienced by all individuals and classified as acute and chronic pain. NSAID's were most widely used for treatment of Analgesia and Inflammation. Ibuprofen, Ketoprofen, Polyethylene glycol 1500 \& PEG 6000 were used as drug carriers and Glycine was used as spacer to link the drugs through ester linkage. Ibuprofen and Ketoprofen belong to propionic acid derivatives of Anti-inflammatory drugs and are non-selective COX inhibitors. PEG 1500/PEG6000-Ibuprofen/Ketoprofen and PEG 1500/PEG 6000-Glycine-Ibuprofen/Ketoprofen were synthesized and are subjected to In Vitro dissolution studies which revealed that the drug release was higher at $7.2 \mathrm{pH}$ rather than at $1.2 \mathrm{pH}$. The results of In Vivo evaluation studies of both synthesized prodrugs revealed that these prodrugs retained their Analgesic activity by hot plate method and acetic acid method, Antiinflammatory activity by paw edema method and cotton pellet method. Both the prodrugs had exhibited good ulcer protective activity when compared to parent drugs.
\end{abstract}

Keywords: Prodrugs, Polyethylene Glycol 1500, Poly Ethylene Glycol 6000, Ibuprofen, Ketoprofen.

Article Info: Received 14 March, 2018; Review Completed 01 June 2018; Accepted 04 June 2018; Available online 15 July 2018 Cite this article as:

Kemisetti D, Manda S, Synthesis and comparison of PEG-lbuprofen and PEG-Ketoprofen prodrugs by in vitro and in vivo evaluation, Journal of Drug Delivery and Therapeutics. 2018; 8(4):145-154 DOI: http://dx.doi.org/10.22270/jddt.v8i4.1743

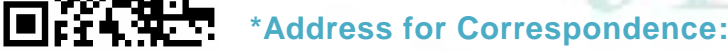

Durgaprasad Kemisetti, Associate Professor, Vaagdevi Pharmacy College, Bollikunta, Warangal-506005, India

\section{INTRODUCTION}

Pain is an unpleasant sensation experienced by all individuals may be after an injury. Pain is classified as acute pain and chronic pain. Acute pain is a localized short term pain after an injury, which can be controlled by using NSAID's, where as chronic pain is long term pain lasting from days to months, where NSAID's have to be used for long term ${ }^{1-4,}{ }^{12-13}$. NSAID's were used most widely all over the world for treatment of analgesia and inflammation ${ }^{5}$.

Inflammation is a host defense mechanism, which involves a complex network of cell-cell, cell-mediator and tissue interactions. Inflammation is regarded as an injury to cell or tissue after trauma or post operative surgery. Prostaglandins play an important role in the inflammation process. The mechanism of all NSAID drugs is by inhibiting cyclooxygenase (COX) enzyme which is required for conversion of arachidonic acid to prostaglandin $\mathrm{E}_{2}\left(\mathrm{PGE}_{2}\right)$. COX enzyme occurs in two forms COX1 (cyclooxygenase1) and COX2 (cyclooxygenase2) ${ }^{1,}$ 6-11 . Inhibition of COX2 enzymes led to anti-inflammatory activity, whereas COX1 for ulcer protective activity ${ }^{4,12}$. Ibuprofen and Ketoprofen belongs to Propionic acid derivatives of NSAID classification $^{14}$.

Prodrugs are the compounds which are inactive themselves, but are converted to active form at the site of action. They are useful in overcoming the problems viz poor membrane permeability, toxicity, taste, shorter duration of action etc. These prodrugs are converted into 
their active form by enzyme degradation in the body. Prodrugs are the molecules which undergo chemical or biochemical conversion before exerting pharmacological activity ${ }^{15}$. The main reason for designing prodrugs are to overcome the adverse effects or limitations, which are associated with parent drugs, such as stability, absorption, solubility, rapid elimination, lack of target delivery ${ }^{16}$.

Most commonly prodrugs require hydrolytic cleavage mediated by enzymatic catalysis. The drugs containing carboxyl, hydroxyl or amino groups are converted to prodrug esters or amides from which the drug is hydrolyzed by enzymes like esterases and peptidases.

Ideal properties of prodrug include

1. Rapid transformation chemically/enzymatically cleaved into active form.

2. Does not have intrinsic pharmacological activity.

3. Metabolic fragment apart from active drug should be nontoxic.

4. Obtain drug targeting using site specific biotransformation/site specific transporters.

An approach for designing usage of drugs with improved therapeutic use was developing polymeric prodrugs or polymer-drug conjugates. Any polymer can be covalently attached to any class of drugs promising better drug characteristics and activity ${ }^{17}$.

\section{Ideal properties required for polymer}

1. It should be inert

2. Non toxic, Non immunogenic

3. Functional groups required for covalent binding

4. Availability

5. Bio compatibility, biodegradable, easily excreted ${ }^{17-26}$.

\section{Classification of Polymers}

Polymers with carbon chain backbone: Poly ethyleneglycol, poly propylene, polystyrene, poly (vinyl alcohol), polyacrylamide, poly vinyl pyrrolidone (PVP).

Polymeric prodrugs was first proposed by H. Ringsdorf 1975 which involves drug, polymeric backbone as carrier and spacer linked to drug with polymeric backbone $20,24,27-29$.

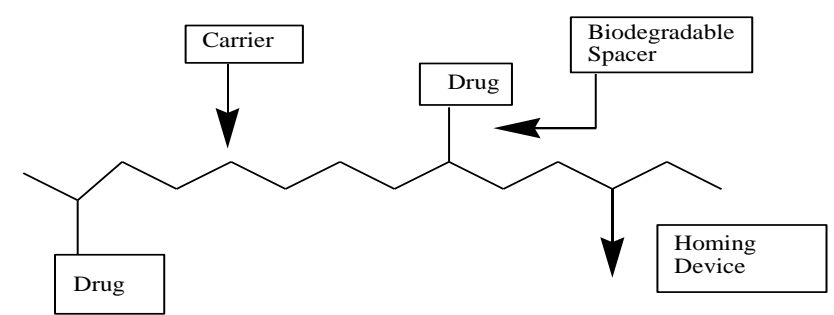

The Ringsdorf model

Figure 1: ${ }^{13}$

\section{Objective}

Based on the literatures synthesis of prodrugs was aimed by using Poly ethylene glycol 1500 and Poly ethylene glycol 6000 as polymeric backbone and Glycine an amino acid as spacer.

\section{MATERIAL AND METHODS}

Poly ethylene glycol 1500/6000, Ibuprofen, Ketoprofen, Pyridine, Thionyl chloride, Dicyclohexyl carbodiimide, Dimethyl amino pyridine, Dimethyl formamide, Diethyl ether.

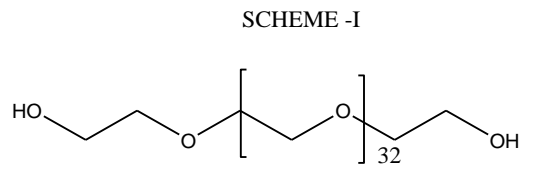

$$
\text { POLY ETHYLENE GLYCOL 1500/6000 }
$$

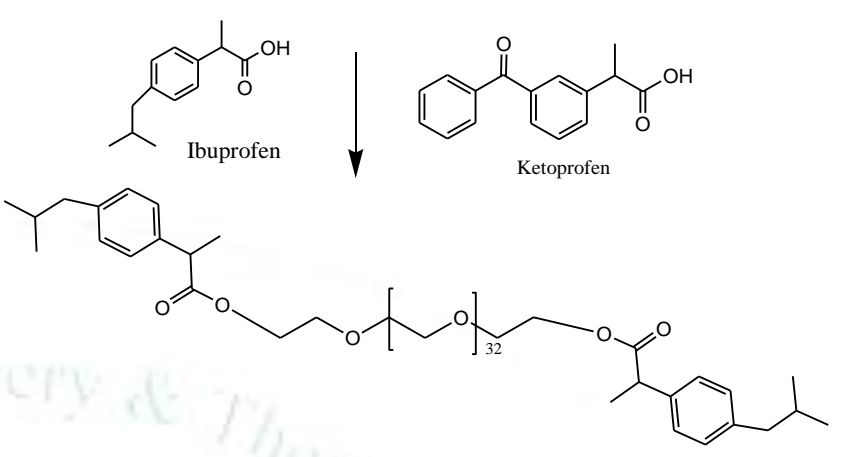

POLY ETHYLENE GLYCOL 1500/6000- IBUPROFEN

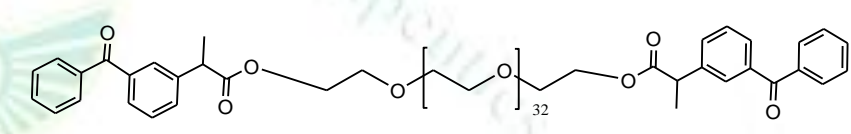

POLY ETHYLENE GLYCOL 1500/6000- KETOPROFEN

SCHEME-II

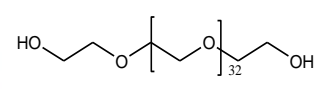

POLY ETHYLENE GLYCOL 1500/6000
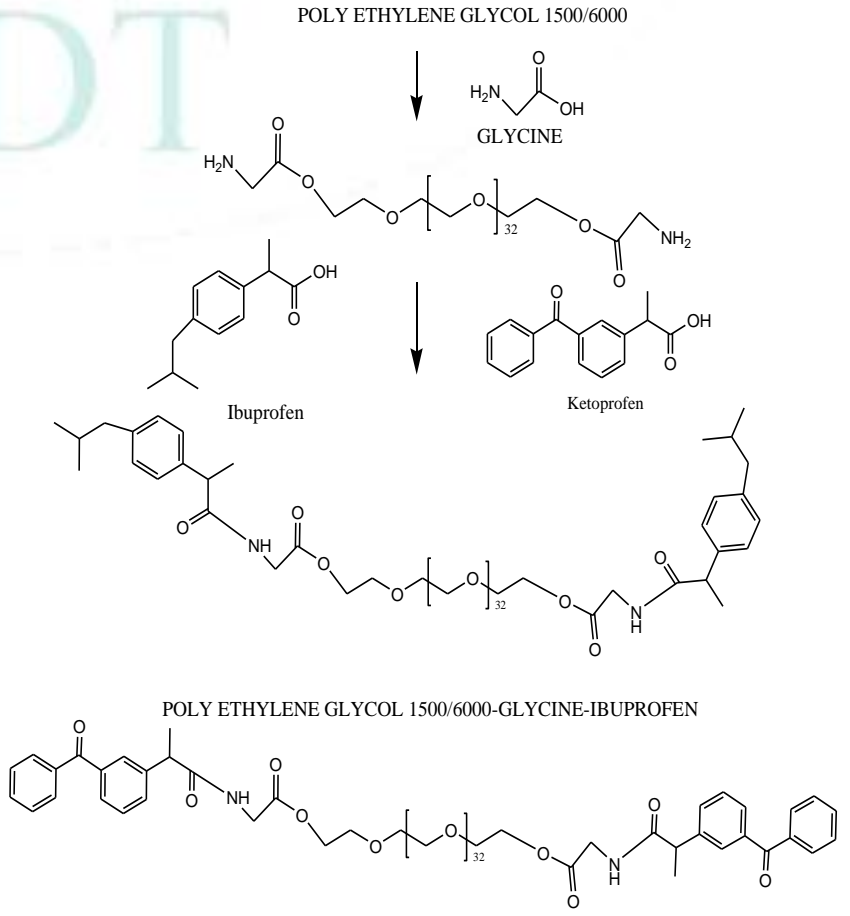

POLY ETHYLENE GLYCOL 1500/6000-GLYCINE-KETOPROFEN 


\section{Preparation of PEG (1500 \& 6000)-Ibuprofen and Ketoprofen}

Accurately weighed $1.5 \mathrm{~g}$ of PEG $1500 / 6000$ and $1.6 \mathrm{ml}$ of pyridine were taken in a round bottom flask, to it $1 \mathrm{~g}$ accurately weighed DCC (dicyclohexyl carbodiimide) and $0.6 \mathrm{~g}$ of DMAP (dimethyl amino pyridine) previously dissolved in $10 \mathrm{ml}$ of DMF (dimethyl formamide) was taken.. The flask was then kept in an ice bath and the temperature was maintained at $0^{\circ} \mathrm{C}$. To the flask $0.5 \mathrm{~g}$ of the drugs (Ibuprofen and Ketoprofen) was added, slowly for $10 \mathrm{~min}$. The contents of the flask were stirred for 7 days to complete the coupling reaction using magnetic stirrer at room temperature. The product obtained was dissolved in dichloro methane and dried over anhydrous potassium carbonate and filtered. The filtrate was then treated with Neutral Alumina and then reprecipitated by excess of cold Diethyl ether ${ }^{30}$.

\section{Preparation of PEG (1500 \& 6000)-Glycine- Ibuprofen and Ketoprofen}

Accurately weighed $1 \mathrm{~g}$ of DCC and $0.6 \mathrm{~g}$ of DMAP were taken in different beakers and dissolved in $10 \mathrm{ml}$ of DMF individually. Then DMAP solution was added to DCC solution. Accurately weighed $0.4 \mathrm{~g}$ of PEG 1500/6000-Glycine was taken in a beaker and dissolved in $20 \mathrm{ml}$ of DMF. The above solution of DCC and DMAP was added to PEG 1500/6000-Glycine solution drop by drop. Accurately weighed $1 \mathrm{~g}$ of drug (Ibuprofen and Ketoprofen) was added to the above solution and the temperature was maintained at $0^{\circ} \mathrm{C}$ for $10 \mathrm{~min}$. The contents were transferred to a round bottom flask with a magnetic bead and fitted with a condenser. The flask was placed on a magnetic stirrer. The coupling reaction was carried out for 7 days at room temperature. The filtrate was then treated with Neutral Alumina and reprecipitated by excess of cold Diethyl ether.

All the synthesized compounds i.e. PEG1500-Ibuprofen, PEG6000-Ibuprofen, PEG1500-Gly-Ibuprofen, PEG6000-Gly-Ibuprofen, PEG1500-Ketoprofen, PEG6000-Ketoprofen, PEG1500-Gly-Ketoprofen and PEG6000-Gly-Ketoprofen were characterized by I.R and N.M.R and compared with in vitro dissolution studies and in vivo analgesic, anti inflammatory and ulcer protecting activity.

\section{In vitro drug release}

The $\lambda_{\max }$ of pure drugs Ibuprofen and Ketoprofen were determined and found to be 264 and $256 \mathrm{~nm}$ respectively. The standard drugs and prodrugs were subjected for drug release at $\mathrm{pH} 1.2$ and 7.2 and $37 \pm 0.5^{\circ}$ $\mathrm{C}$ individually and \% cumulative drug release was noted using standard graph. A graph was plotted \% cumulative drug release $\mathrm{v} / \mathrm{s}$ time in min.

\section{Analgesic Activity}

For the study of analgesic activity the models chosen were Hotplate method and Acetic acid-induced writhing.

\section{Hotplate method}

For the analgesic activity by this method, according to Institutional animal ethical committee (IAEC
1648/PO/a/12/CPCSEA-GCOP-IAEC-03/2013), the rats were divided into Six groups consisting of 6 animals each and checked for jump response ${ }^{31-34}$.

\section{Acetic acid-induced writhing method}

For the study by this method the rats were divided into 6 groups consisting of 6 animals each. Acetic acid was used to induce writhings. Ist group was administered acetic acid intra peritoneally and recorded for the onset of wriths over a period of 15 minutes and after $3 \mathrm{hrs}$ acetic acid was administered and number of wriths were noted and compared with control.

\section{Anti inflammatory Activity}

For assessing anti-inflammatory activity two models were chosen

\section{Carrageenan-induced rat paw edema method}

The animals were divided into 6 groups consisting of 6 animals each. Before injecting the paw volumes of left and right were measured by Dolphin, India Plethysmometer and edema volume was noted as Vo and after injecting standard drugs and prodrugs the volume was noted as $\mathrm{Vt}$. The volume after injection was measured at intervals of $1 \mathrm{hr}, 3 \mathrm{hr}$, and $6 \mathrm{hrs}$. The percentage inhibition of edema was calculated by equation $^{31}$

\section{Cotton pellet induced granuloma method}

The rats were divided into 6 groups consisting of 6 animals each. The rats were anaesthetized with ether, incised and then sterilized cotton pellets $10 \mathrm{mg}$ were implanted subcutaneously on either side of lumbar region. The incision was sutured and each group was treated continuously for 7 days with control, standard and prodrugs. After 7 days on $8^{\text {th }}$ day, the animals were sacrificed and cotton pellets were removed, dried at constant weight for $24 \mathrm{hrs}$ and weighed.

\section{Ulcer Protective Activity}

The method followed for the ulcer protecting activity was Pylorus-ligation. Male Sprague-Dawley rats weighing 100-150 g were fastened overnight, anaesthtized with ether. An incision of $1 \mathrm{~cm}$ long in the abdomen below the sternum was made and stomach was exposed. A thread was passed around pyloric sphincter and tied. The rats were kept in separate cages and allowed to recover ${ }^{35}$. After $4 \mathrm{hrs}$ of the pylorus ligation all the animals including control group were sacrificed, abdomen was cut open and entire stomach was removed and washed under tap water. Then placed on a glass slide and observed on microscope at $10 \mathrm{X}$ magnification for ulcers.

Area of gross damage (ulceration) was measured by computerized video analysis system (Metamorph 7.0 Molecular devices, Downington, PA, USA). Mean ulcer score was expressed as Ulcer Index. 


\section{RESULTS}

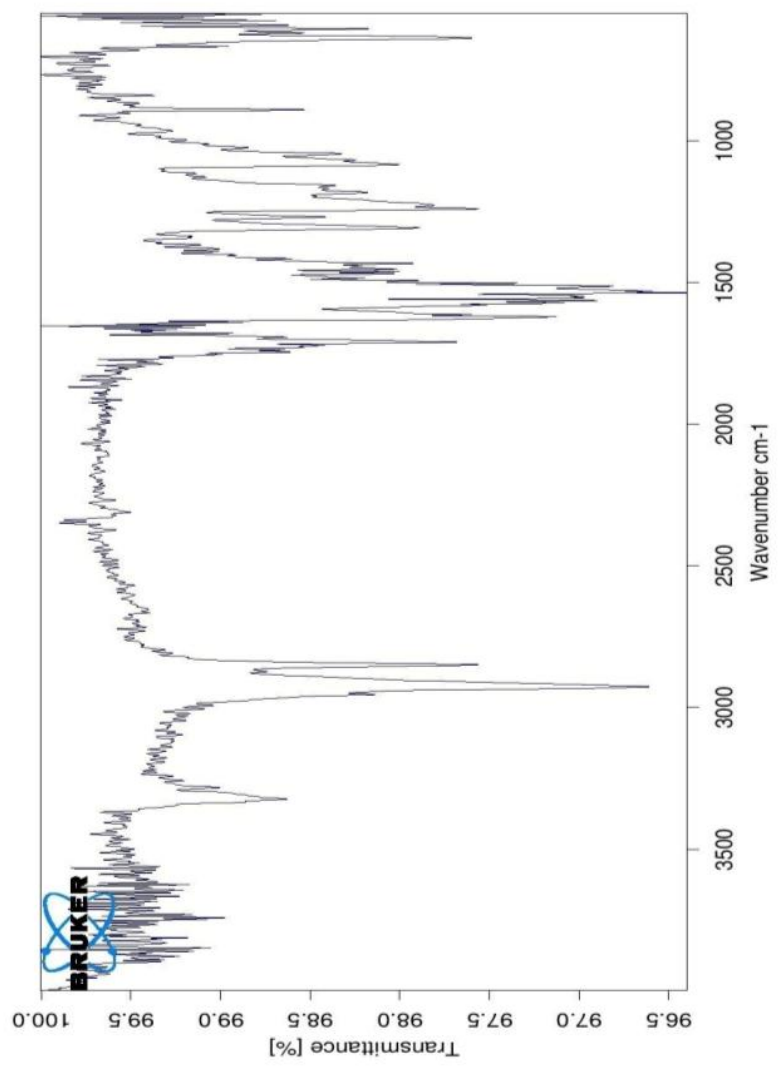

Figure 2: I.R Spectra of PEG 1500/6000-Ibuprofen

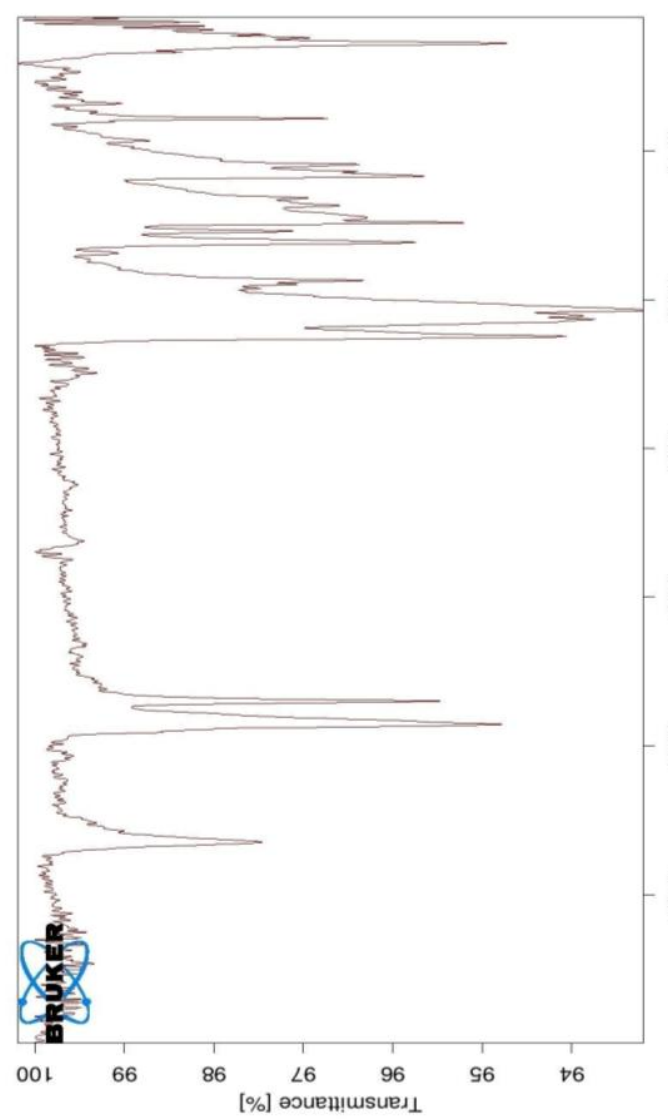

Figure 3: I.R Spectra of PEG 1500/6000-GlycineIbuprofen

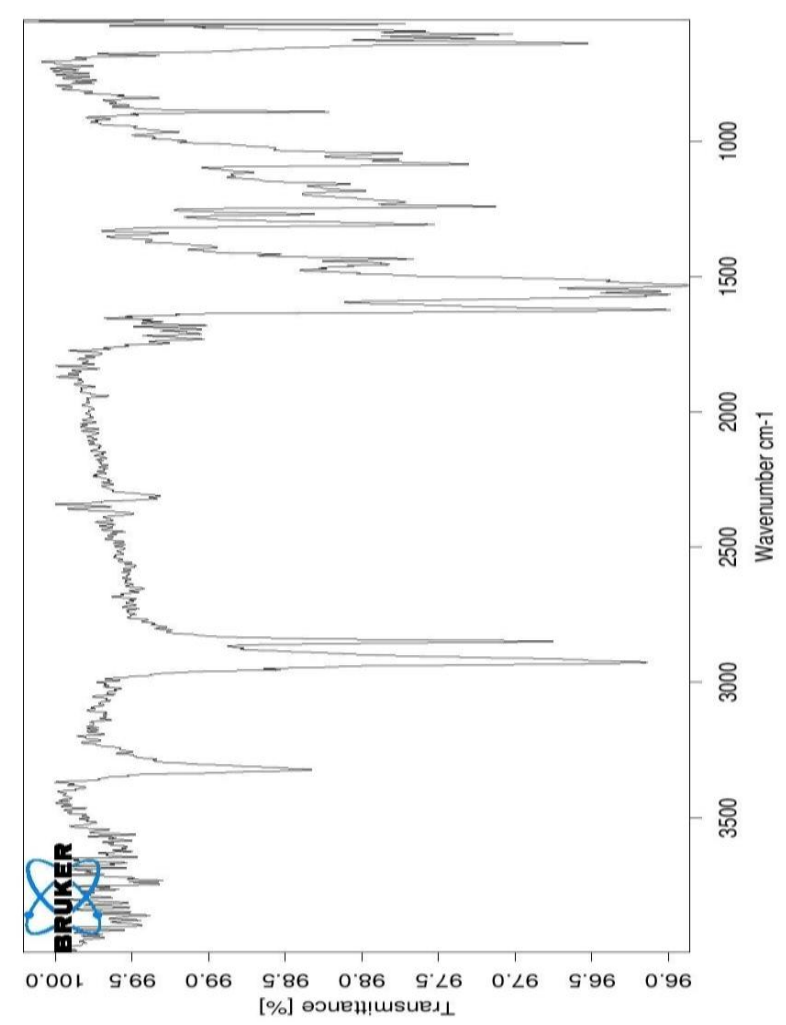

Figure 4: I.R Spectra of PEG 1500/6000-Ketoprofen

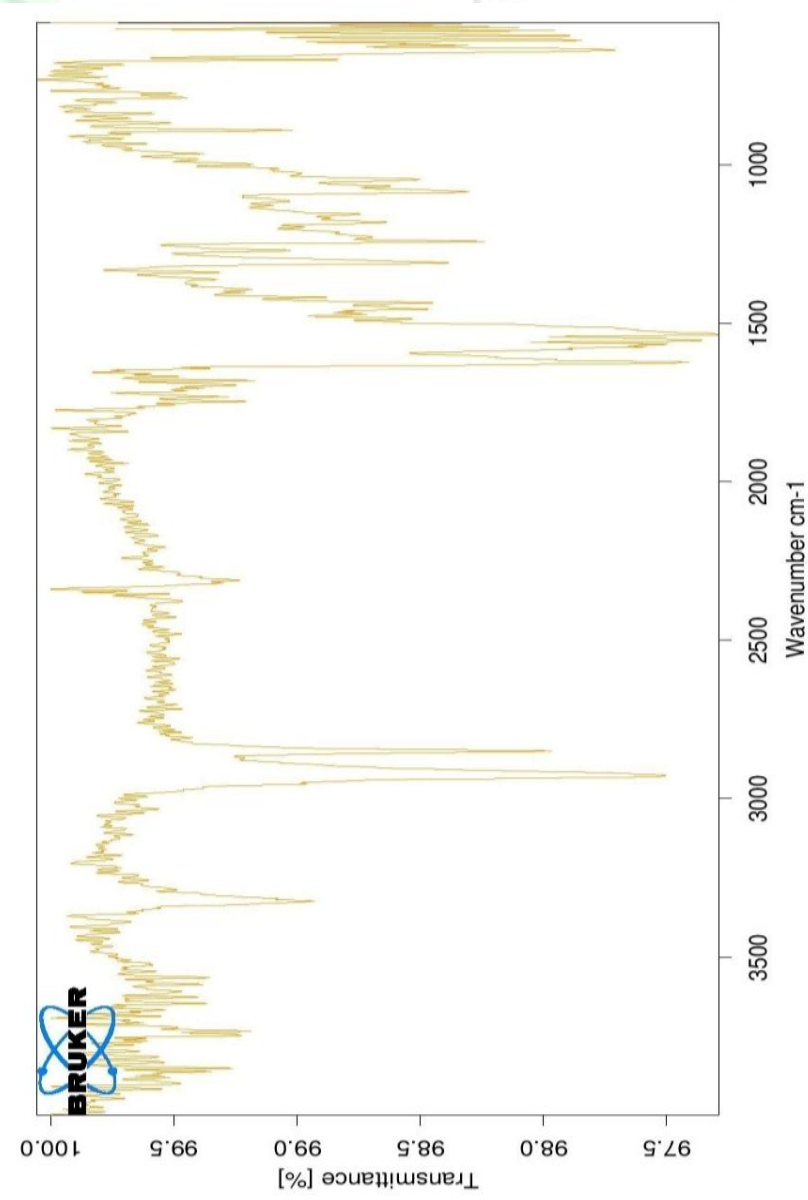

Figure 5: I.R Spectra of PEG 1500/6000-GlycineKetoprofen 


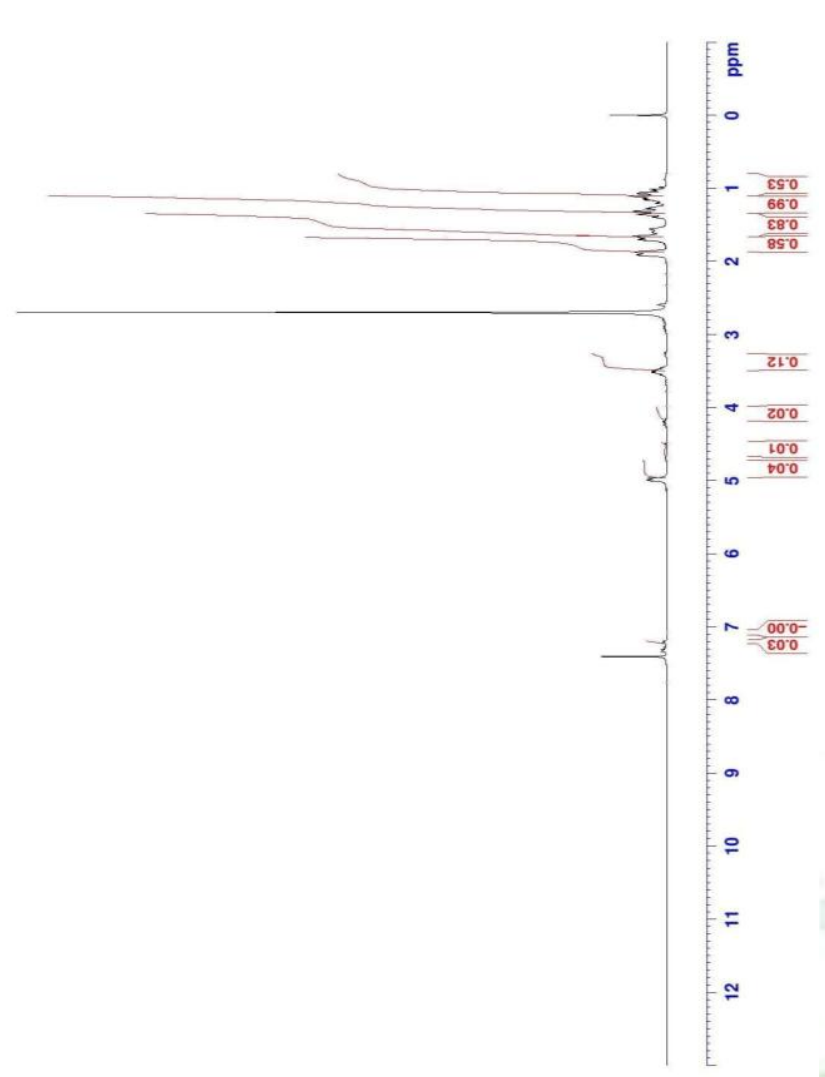

Figure 6: N.M.R Spectra of PEG 1500/6000Ibuprofen

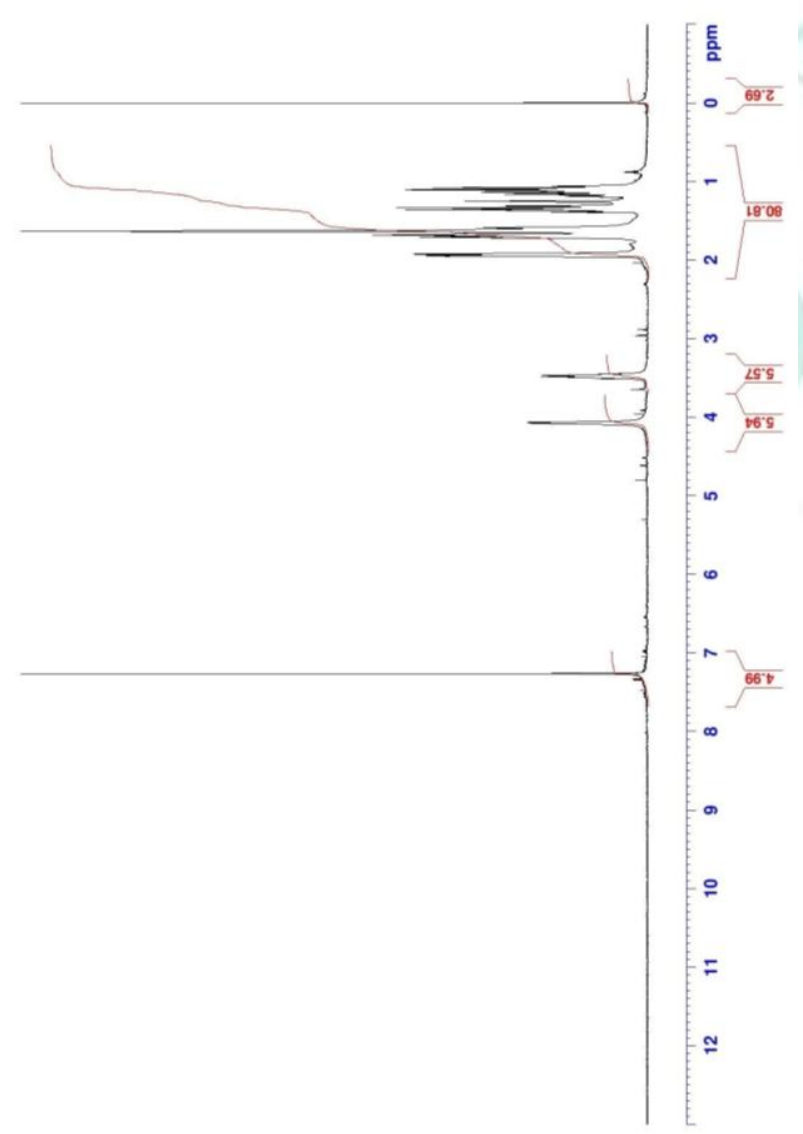

Figure 7: N.M.R Spectra of PEG 1500/6000-GlycineIbuprofen

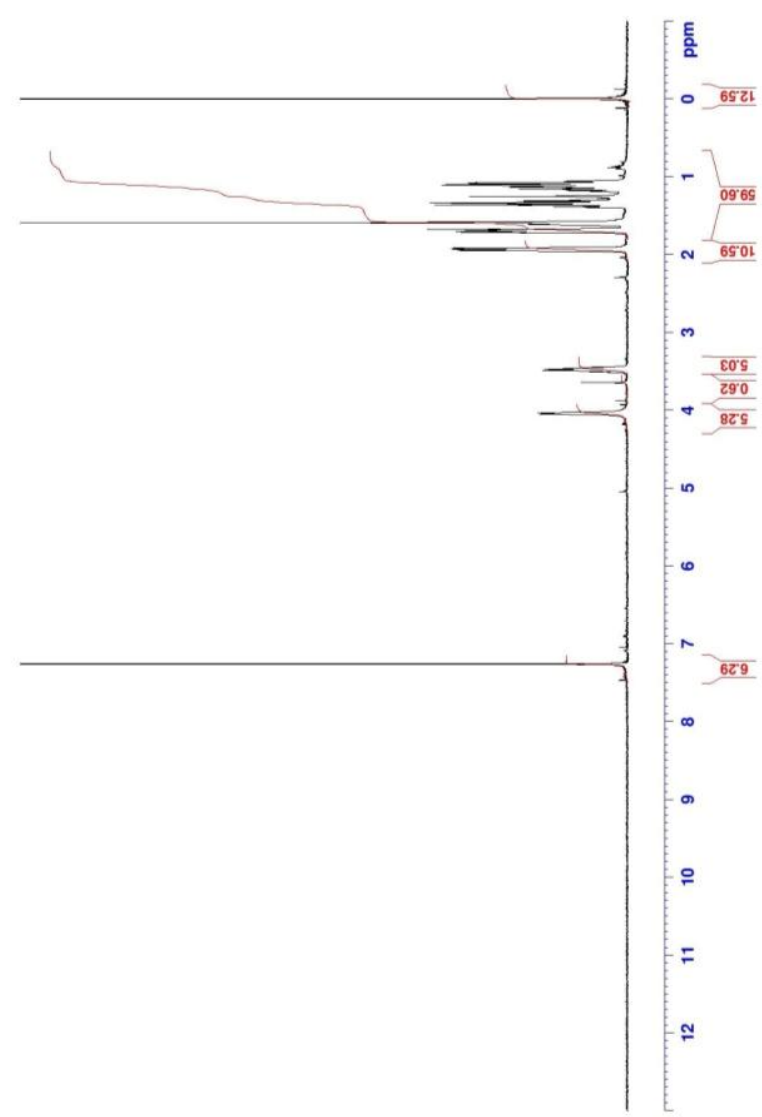

Figure 8: N.M.R Spectra of PEG 1500/6000Ketoprofen

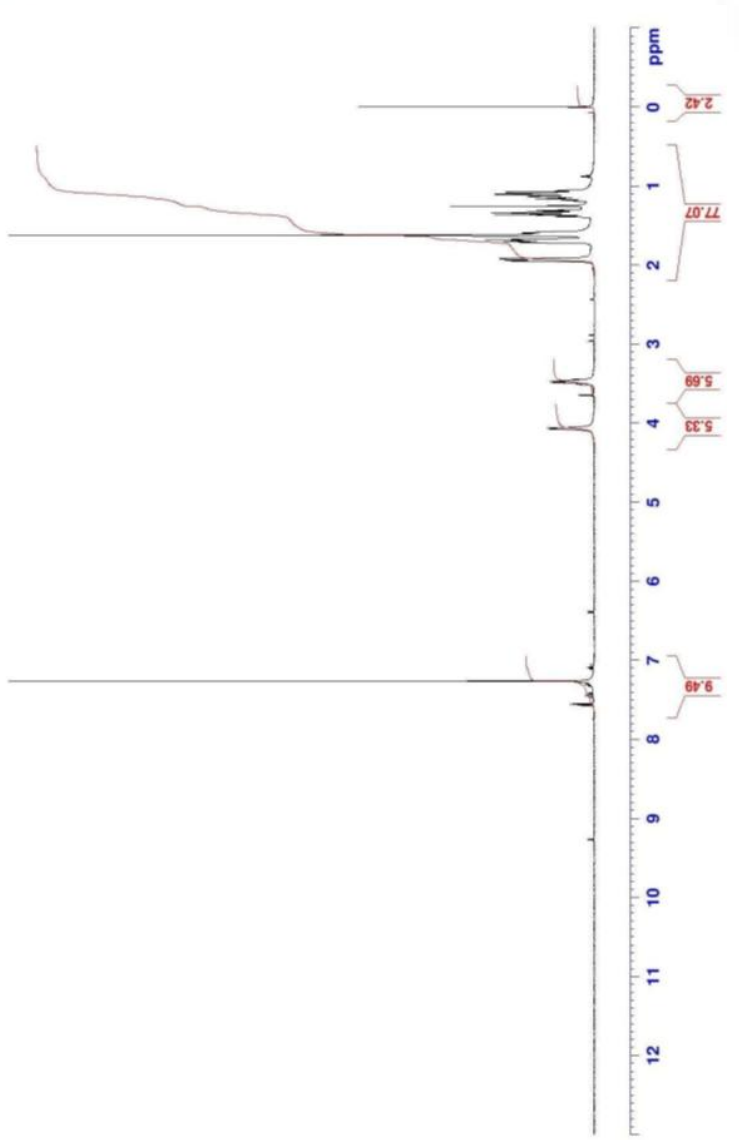

Figure 9: N.M.R Spectra of PEG 1500/6000-GlycineKetoprofen 
Table 1: PEG 1500-Ibuprofen and PEG 1500-Gly-Ibuprofen release at 1.2 \& 7.2.

\begin{tabular}{|c|c|c|c|c|c|}
\hline \multirow{2}{*}{ S.No } & \multirow{2}{*}{ Time in Minutes } & \multicolumn{2}{|c|}{ PEG 1500-Ibuprofen } & \multicolumn{2}{c|}{ PEG 1500-Gly-Ibuprofen } \\
\cline { 3 - 6 } & & pH 1.2 & pH 7.2 & pH 1.2 & pH 7.2 \\
\hline 1 & 0 & 0 & 0 & 0 & 0 \\
\hline 2 & 5 & 11.4 & 12.4 & 10.9 & 10.6 \\
\hline 3 & 10 & 16.4 & 24.7 & 15.4 & 21.8 \\
\hline 4 & 15 & 20.3 & 38.4 & 19.2 & 39.3 \\
\hline 5 & 30 & 21.9 & 46.8 & 20.6 & 55.4 \\
\hline 6 & 45 & 24.1 & 69.1 & 23.7 & 68.9 \\
\hline 7 & 60 & 26.7 & 81.3 & 25.4 & 82.7 \\
\hline
\end{tabular}

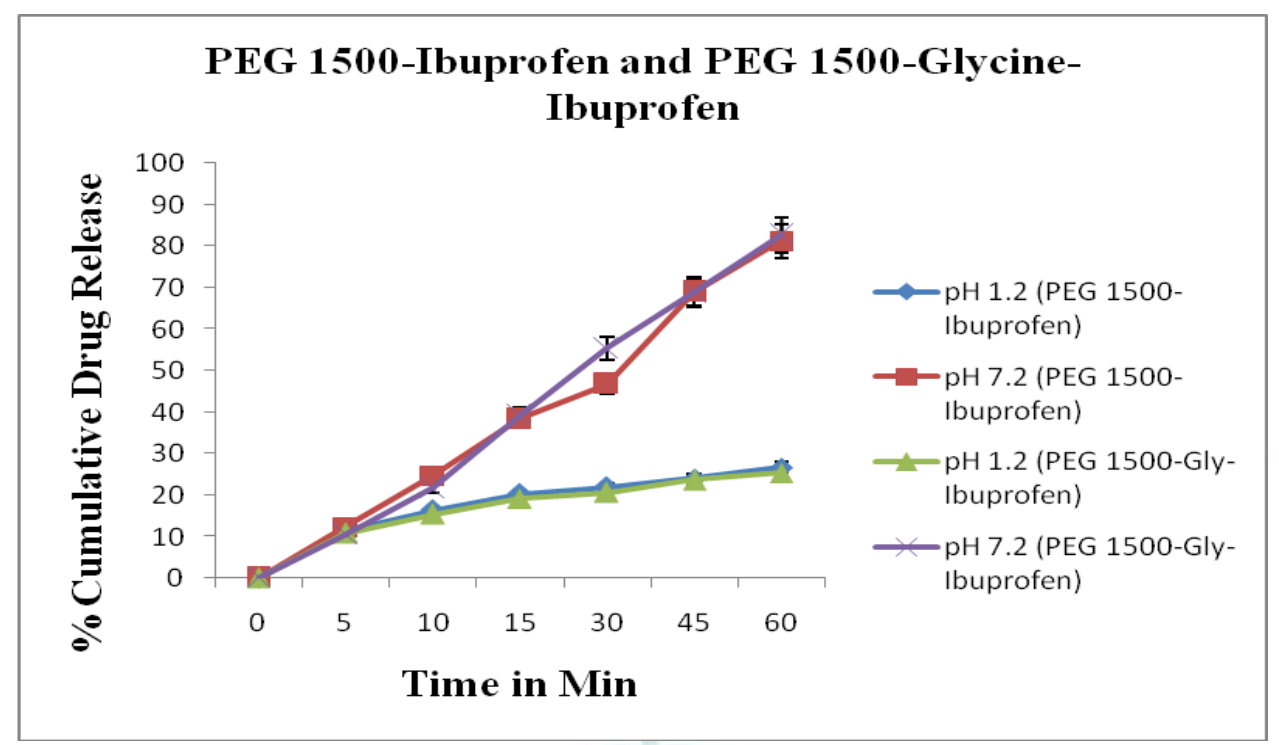

Figure 10: Cumulative drug release of PEG 1500-Ibuprofen \& PEG 1500-Gly-Ibuprofen

Table 2: PEG 6000-Ibuprofen and PEG 6000-Gly-Ibuprofen release at 1.2 \& 7.2.

\begin{tabular}{|c|c|c|c|c|c|}
\hline \multirow{2}{*}{ S.No } & \multirow{2}{*}{ Time in Minutes } & \multicolumn{2}{|c|}{ PEG 6000-Ibuprofen } & \multicolumn{2}{c|}{ PEG 6000-Gly-Ibuprofen } \\
\cline { 3 - 6 } & & $\mathbf{p H ~ 1 . 2}$ & $\mathbf{p H ~ 7 . 2}$ & $\mathbf{p H ~ 1 . 2}$ & pH 7.2 \\
\hline 1 & 0 & 0 & 0 & 0 & 0 \\
\hline 2 & 5 & 8.9 & 14.2 & 7.6 & 15.7 \\
\hline 3 & 10 & 10.5 & 26.9 & 10.2 & 29.1 \\
\hline 4 & 15 & 15.7 & 39.6 & 12.9 & 49.6 \\
\hline 5 & 30 & 20.9 & 49.2 & 18.7 & 59.4 \\
\hline 6 & 45 & 22.7 & 68.7 & 20.3 & 72.7 \\
\hline 7 & 60 & 26.8 & 83.8 & 24.1 & 84.6 \\
\hline
\end{tabular}

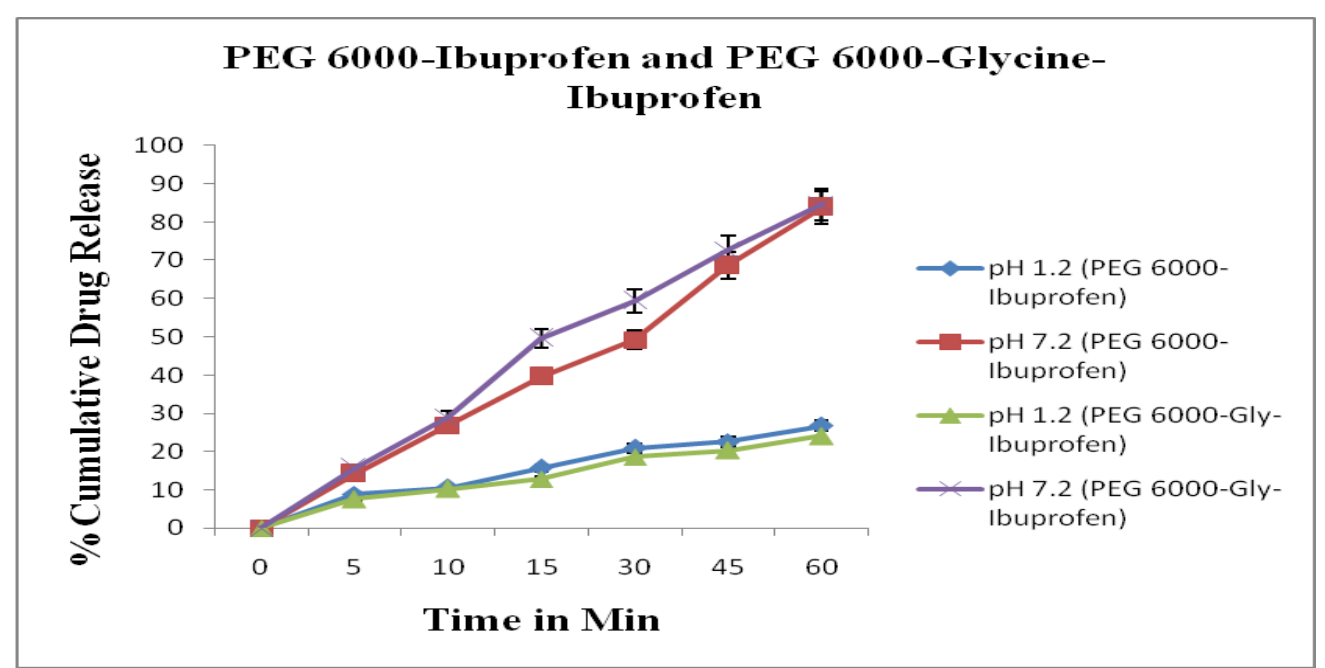

Figure 11: Cumulative drug release of PEG 6000-Ibuprofen \& PEG 6000-Gly-Ibuprofen 
Table 3: PEG 1500-Ketoprofen and PEG 1500-Gly-Ketoprofen release at $1.2 \&$ 7.2.

\begin{tabular}{|c|c|c|c|c|c|}
\hline \multirow{2}{*}{ S.No } & \multirow{2}{*}{ Time in Minutes } & \multicolumn{2}{|c|}{ PEG 1500-Ketoprofen } & \multicolumn{2}{c|}{ PEG 1500-Gly-Ketoprofen } \\
\cline { 3 - 5 } & & pH 1.2 & pH 7.2 & pH 1.2 & pH 7.2 \\
\hline 1 & 0 & 0 & 0 & 0 & 0 \\
\hline 2 & 5 & 12.8 & 16.7 & 11.4 & 17.2 \\
\hline 3 & 10 & 14.7 & 29.2 & 13.8 & 31.4 \\
\hline 4 & 15 & 16.9 & 38.6 & 15.7 & 39.4 \\
\hline 5 & 30 & 19.3 & 46.1 & 17.8 & 47.9 \\
\hline 6 & 45 & 22.5 & 68.3 & 22.9 & 69.4 \\
\hline 7 & 60 & 24.1 & 84.6 & 26.7 & 85.7 \\
\hline
\end{tabular}

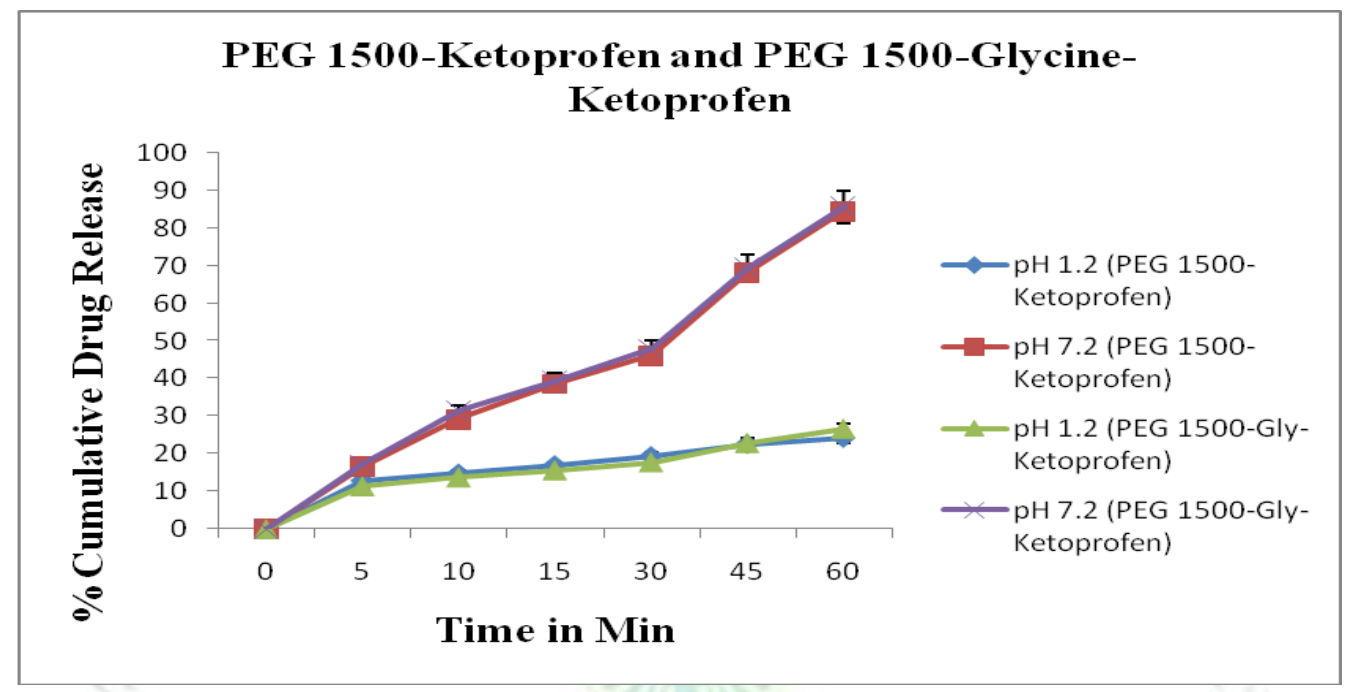

Figure 12: Cumulative drug release of PEG 1500-Ketoprofen \& PEG 1500-Gly-Ketoprofen

Table 4: PEG 6000-Ketoprofen and PEG 6000-Gly-Ketorpofen release at 1.2 \& 7.2.

\begin{tabular}{|c|c|c|c|c|c|}
\hline \multirow{2}{*}{ S.No } & Time in Minutes & \multicolumn{2}{|c|}{ PEG 6000-Ketoprofen } & \multicolumn{2}{c|}{ PEG 6000-Gly-Ketoprofen } \\
\cline { 3 - 6 } & & pH 1.2 & pH 7.2 & pH 1.2 & pH 7.2 \\
\hline 1 & 0 & 0 & 0 & 0 & 0 \\
\hline 2 & 5 & 11.5 & 13.7 & 12.3 & 12.8 \\
\hline 3 & 10 & 15.2 & 25.8 & 15.7 & 20.1 \\
\hline 4 & 15 & 17.4 & 37.8 & 18.4 & 36.9 \\
\hline 5 & 30 & 19.7 & 48.7 & 20.7 & 46.7 \\
\hline 6 & 45 & 20.8 & 69.7 & 23.5 & 68.1 \\
\hline 7 & 60 & 23.9 & 84.7 & 26.8 & 86.7 \\
\hline
\end{tabular}

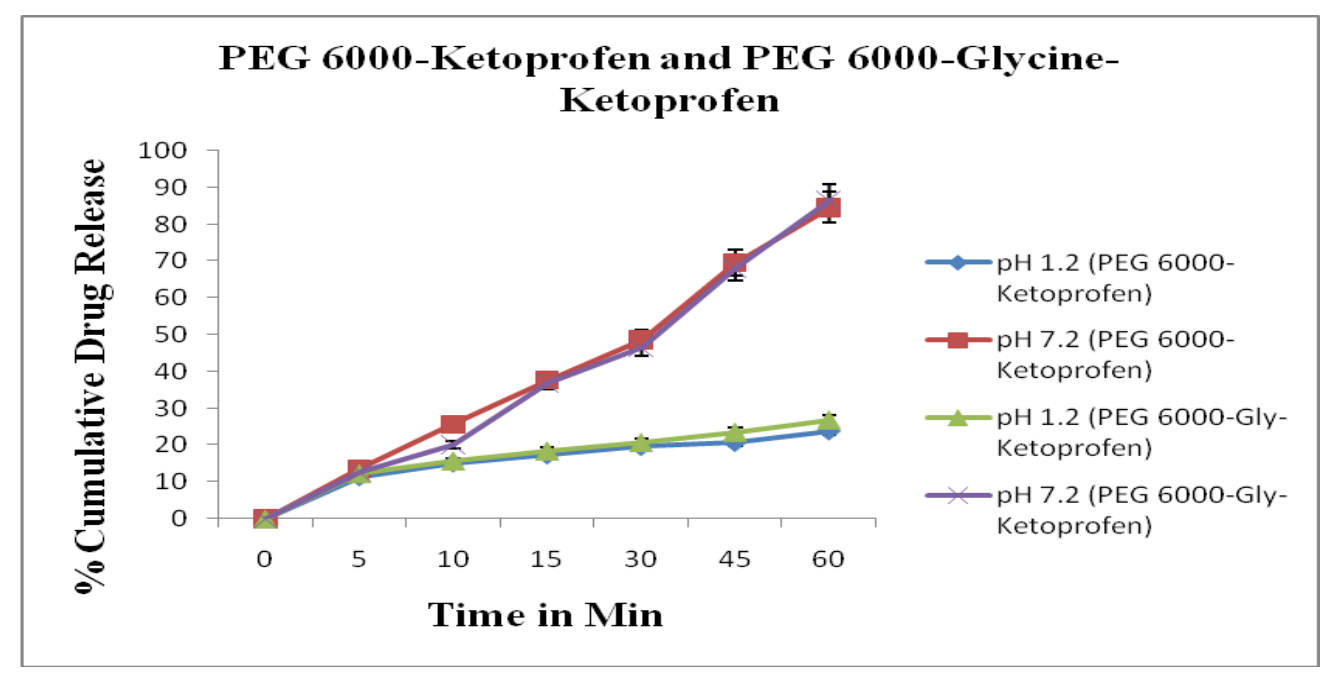

Figure 13: Cumulative drug release of PEG 6000-Ketoprofen \& PEG 6000-Gly-Ketoprofen 


\section{Analgesic Activity: Hotplate Method}

Table 5: Analgesic activity of Ibuprofen/Ketoprofen and synthesized prodrugs

\begin{tabular}{|l|l|l|}
\hline Groups & $\begin{array}{l}\text { \% Inhibition } \\
\text { Ibuprofen }\end{array}$ & $\begin{array}{l}\text { \% Inhibition } \\
\text { Ketoprofen }\end{array}$ \\
\hline Control & 0 & 0 \\
\hline Ibuprofen/ketoprofen & 62.0 & 63.5 \\
\hline PEG 1500-Ibuprofen/ ketoprofen & 65.7 & 72.3 \\
\hline PEG 1500-Glycine-Ibuprofen/ ketoprofen & 98.3 & 76.2 \\
\hline PEG 6000-Ibuprofen/ ketoprofen & 73.6 & 90.3 \\
\hline PEG 6000-Glycine-Ibuprofen/ ketoprofen & 52.8 & 97.5 \\
\hline
\end{tabular}

Acetic acid method

Table 6: Analgesic activity of Ibuprofen and synthesized prodrugs

\begin{tabular}{|l|l|l|}
\hline Groups & $\begin{array}{l}\text { \% Inhibition } \\
\text { Ibuprofen }\end{array}$ & $\begin{array}{l}\text { \% Inhibition } \\
\text { Ketoprofen }\end{array}$ \\
\hline Control & 0 & 0 \\
\hline Ibuprofen/Ketoprofen & 74.3 & 68.3 \\
\hline PEG 1500-Ibuprofen/Ketoprofen & 85.8 & 83.0 \\
\hline PEG 1500-Glycine-Ibuprofen/Ketoprofen & 92.7 & 88.1 \\
\hline PEG 6000-Ibuprofen/Ketoprofen & 89.0 & 86.3 \\
\hline PEG 6000-Glycine-Ibuprofen/Ketoprofen & 84.0 & 92.1 \\
\hline
\end{tabular}

Antiinflammatory Activity: Paw edema method

Table 7: Anti inflammatory activity of Ibuprofen and synthesized prodrugs

\begin{tabular}{|c|c|c|c|}
\hline \multirow{2}{*}{ Groups } & \multicolumn{3}{|c|}{ Change in Paw volume (ml) mean \pm SEM \& \% Inhibition } \\
\cline { 2 - 4 } & $\mathbf{1 ~ h r}$ & $\mathbf{3 ~ h r}$ & $\mathbf{6 ~ h r}$ \\
\hline Control & $0.47 \pm 0.01$ & $0.59 \pm 0.01$ & $0.65 \pm 0.02$ \\
\hline Ibuprofen & $0.24 \pm 0.02(48.93)$ & $0.22 \pm 0.01(62.7)$ & $0.19 \pm 0.01(70.76)$ \\
\hline PEG1500-Ibuprofen & $0.19 \pm 0.01(59.57)$ & $0.18 \pm 0.02(69.49)$ & $0.17 \pm 0.03(73.84)$ \\
\hline PEG1500-Gly-Ibuprofen & $0.17 \pm 0.01(63.82)$ & $0.13 \pm 0.02(77.96)$ & $0.11 \pm 0.02(83.07)$ \\
\hline PEG6000-Ibuprofen & $0.16 \pm 0.01(65.95)$ & $0.09 \pm 0.01(84.74)$ & $0.08 \pm 0.01(87.69)$ \\
\hline PEG6000-Gly-Ibuprofen & $0.18 \pm 0.01(61.7)$ & $0.15 \pm 0.02(74.57)$ & $0.14 \pm 0.02(78.46)$ \\
\hline \multicolumn{2}{|c|}{ Values are mean \pm SEM, $\mathrm{n}=6$, one way ANOVA p<0.05 vs control }
\end{tabular}

Antiinflammatory Activity: Paw edema method

Table 8: Anti inflammatory activity of Ketoprofen and synthesized prodrugs

\begin{tabular}{|c|c|c|c|}
\hline \multirow{2}{*}{ Groups } & \multicolumn{2}{|c|}{ Change in Paw volume (ml) mean \pm SEM \& \% Inhibition } \\
\cline { 2 - 4 } & $\mathbf{1 ~ h r}$ & $\mathbf{3 ~ h r}$ & $\mathbf{6 ~ h r}$ \\
\hline Control & $0.47 \pm 0.01$ & $0.59 \pm 0.01$ & $0.65 \pm 0.02$ \\
\hline Ketoprofen & $0.23 \pm 0.02(51.06)$ & $0.20 \pm 0.01(66.1)$ & $0.18 \pm 0.01(72.3)$ \\
\hline PEG1500-Ketoprofen & $0.16 \pm 0.01(65.95)$ & $0.12 \pm 0.02(79.66)$ & $0.11 \pm 0.02(83.07)$ \\
\hline PEG1500-Gly-Ketoprofen & $0.17 \pm 0.01(63.82)$ & $0.15 \pm 0.02(74.57)$ & $0.13 \pm 0.02(80.00)$ \\
\hline PEG6000-Ketoprofen & $0.14 \pm 0.01(70.21)$ & $0.09 \pm 0.01(84.74)$ & $0.08 \pm 0.02(87.69)$ \\
\hline PEG6000-Gly-Ketoprofen & $0.18 \pm 0.01(61.7)$ & $0.16 \pm 0.02(72.88)$ & $0.15 \pm 0.03(76.92)$ \\
\hline
\end{tabular}

Values are mean \pm SEM, $n=6$, one way ANOVA $p<0.05$ vs control 
Cotton pellet method

Table 9: Anti inflammatory activity of Ibuprofen and Ketoprofen synthesized prodrugs

\begin{tabular}{|l|l|l|}
\hline Groups & $\begin{array}{c}\text { \% Inhibition } \\
\text { Ibuprofen }\end{array}$ & $\begin{array}{c}\text { \% Inhibition } \\
\text { Ketoprofen }\end{array}$ \\
\hline Control & 0 & 0 \\
\hline Ibuprofen/Ketoprofen & 59.5 & 57.7 \\
\hline PEG 1500-Ibuprofen/Ketoprofen & 68.4 & 61.8 \\
\hline PEG 1500-Glycine-Ibuprofen/Ketoprofen & 66.5 & 60.3 \\
\hline PEG 6000-Ibuprofen/Ketoprofen & 69.8 & 70.0 \\
\hline PEG6000-Glycine-Ibuprofen/Ketoprofen & 65.5 & 67.0 \\
\hline
\end{tabular}

Ulcer Protecting Activity

Table 10: Gross Ulcer Index of Ibuprofen and synthesized prodrugs

\begin{tabular}{|l|l|c|c|}
\hline S.No & Treatment & Ulcer Index & Ulcer Index \\
\hline 1. & Control & 10 & 10 \\
\hline 2. & Ibuprofen/Ketoprofen & 23 & 19 \\
\hline 3. & PEG1500-Ibuprofen/Ketoprofen & 16 & 17 \\
\hline 4. & PEG1500-Gly-Ibuprofen/Ketoprofen & 12 & 12 \\
\hline 5. & PEG6000-Ibuprofen/Ketoprofen & 18 & 15 \\
\hline 6. & PEG6000-Gly-Ibuprofen/Ketoprofen & 17 & 10 \\
\hline
\end{tabular}

\section{DISCUSSION}

\section{PEG 1500/6000-IBUPROFEN}

I.R- C-O-C- $1110 \mathrm{~cm}^{-1}, \mathrm{CH}$ str- 2850, $2950 \mathrm{~cm}^{-1}, \mathrm{C}-\mathrm{O}$ str- $1180 \mathrm{~cm}^{-1}, \mathrm{C}=\mathrm{O}-1625,1670 \mathrm{~cm}^{-1}$, Di substituted Benzene- $730 \mathrm{~cm}^{-1}, 945 \mathrm{~cm}^{-1}$, Aromatic CH- $1254 \mathrm{~cm}^{-1}$.

N.M.R- 0.9-1.2 $\delta-\mathrm{CH}_{3}$ protons (m) (9), 1.2-2.5 $\delta-\mathrm{CH}_{2}$ protons $(\mathrm{m}), 2.6-2.8 \delta \mathrm{CH}$ protons $(\mathrm{q})(2), 3.2-7.4 \delta$ Benzene (m) (8).

\section{PEG 1500/6000-GLYCINE-IBUPROFEN}

I.R- C-O-C- $1080 \mathrm{~cm}^{-1}$, CH str- 2850, $2950 \mathrm{~cm}^{-1}, \mathrm{C}-\mathrm{O}$ str- $1130 \mathrm{~cm}^{-1}, \mathrm{C}-\mathrm{C}$ str- $1250 \mathrm{~cm}^{-1}, \mathrm{C}=\mathrm{O}-1520,1530$, $1580,1600 \mathrm{~cm}^{-1}$, C-N str- $1385 \mathrm{~cm}^{-1}$, Aliphatic NH$3421,3440 \mathrm{~cm}^{-1}$, Di substituted Benzene- $740 \mathrm{~cm}^{-1}, 950$ $\mathrm{cm}^{-1}$, Aromatic CH- $1480 \mathrm{~cm}^{-1}$.

N.M.R- 1.1-1.3 $\delta-\mathrm{CH}_{3}$ protons (m) (18), 1.2-1.9 $\delta-\mathrm{CH}_{2}$ protons (m) (62), $3.3-3.5 \delta$-CH (q) (4), 4.1-7.3 $\delta$ Benzene (m) (8), $3.5 \delta$-NH (d) (2).

\section{PEG 1500/6000-KETOPROFEN}

I.R- C-O-C- $1110 \mathrm{~cm}^{-1}, \mathrm{CH}$ str- 2850, $2950 \mathrm{~cm}^{-1}, \mathrm{C}-\mathrm{O}$ str- $1080 \mathrm{~cm}^{-1}, \mathrm{C}=\mathrm{O}-1580,1600,1620,1660 \mathrm{~cm}^{-1}$, Di substituted Benzene- $770,840 \mathrm{~cm}^{-1}$, Mono substituted Benzene- 750, $950 \mathrm{~cm}^{-1}$, Aromatic CH- $1460 \mathrm{~cm}^{-1}$.

N.M.R- 1.1-1.3 $\delta-\mathrm{CH}_{3}$ protons (m) (6), 1.4-1.9 $\delta-\mathrm{CH}_{2}$ (m) (53), 2.1-2.3 $\delta \mathrm{CH}$ protons (d) (2), 3.4-7.3 $\delta$ Benzene (m) (18).

\section{PEG 1500/6000-GLYCINE-KETOPROFEN}

I.R- C-O-C- $1110 \mathrm{~cm}^{-1}, \mathrm{CH}$ str- 2850, $2950 \mathrm{~cm}^{-1}, \mathrm{C}-\mathrm{O}$ str- $1080 \mathrm{~cm}^{-1}, \mathrm{C}=\mathrm{O}-1525,1535,1560,1585,1600$, $1620 \mathrm{~cm}^{-1}$, C-C str- $1230 \mathrm{~cm}^{-1}$, C-N str- $1375 \mathrm{~cm}^{-1}$, Aliphatic NH-3480, $3530 \mathrm{~cm}^{-1}$, Di substituted Benzene$740,930 \mathrm{~cm}^{-1}$, Mono substituted Benzene- 730, $980 \mathrm{~cm}^{-}$ 1 , Aromatic CH- $1450 \mathrm{~cm}^{-1}$.
N.M.R- $0.7-1.2 \delta-\mathrm{CH}_{3}$ protons (m) (6), 1.3-1.8 $\delta-\mathrm{CH}_{2}$ protons (m) (71), 1.9-2.0 $\delta$ CHprotons (d) (2), 4.1-7.5 $\delta$ Benzene (m) (18), 3.5-3.7 $\delta$ - NH (d) (2).

\section{DISCUSSION}

Based on the results obtained

$>$ Of all the prodrugs synthesized the dissolution studies revealed that their release was higher at $\mathrm{pH}$ 7.2 rather than at $\mathrm{pH} 1.2$.

$>$ Out of the prodrugs synthesized PEG 1500-GlyIbuprofen and PEG 6000-Gly-Ketoprofen have shown maximum effect by Hotplate method and Acetic acid.

$>$ Among the prodrugs synthesized PEG 6000Ibuprofen and PEG 6000-Ketoprofen have shown maximum effect at the end of $6 \mathrm{hrs}$ by Rat paw edema method and Cotton Pellet Method.

$>$ Of all the prodrugs synthesized PEG 1500-GlyIbuprofen and PEG 6000-Gly-Ketoprofen have shown maximum ulcer index indicating ulcer protection as compared to other prodrugs.

\section{CONCLUSION}

It can be concluded that the synthesized polymeric prodrugs had an influence on the drug release pattern effectively at $\mathrm{pH} 7.2$ and had good ulcer protecting activity and Ketoprofen which is a derivative of Ibuprofen had maximum ulcer protecting activity than Ibuprofen.

Acknowledgements: I thank Vaagdevi Pharmacy College for providing me facility to publish my paper.

Conflicts of Interest: The authors have no conflict of interest regarding the publication of this paper. 


\section{REFERENCES}

1. Martindale. The complete drug reference. $\mathrm{PhP}$ Pharmaceutical Press. 2005. P. 1-3.

2. Wang ZJ. Innovative technologies for the research and treatment of pain. Advanced Drug Delivery Reviews, 2003; 55:929-930.

3. Lili X. Wang, Wang ZJ. Animal and cellular models for chronic pain. Advanced Drug Delivery Reviews, 2003; 55:949-965.

4. Praveen Rao P.N., Edward Knaus E. Evolution of Nonsteroidal Anti-inflammatory drugs (NSAIDs): Cyclooxygenase (COX) inhibition and beyond. J Pharm Pharmaceut Sci, 2008; 11(2):81s-110s.

5. Loren L. Approaches to Nonsteroidal Anti-inflammatory drug use in the high-risk patient. Gastroenterology, 2001; 120:594-606.

6. Wilson and Gisvold. Text book of Organic Medicinal and Pharmaceutical chemistry. Lippincotts, Williams and Wilkins. 2004, P, 731-763.

7. Gupta SK, Drug Screening Methods. Jaypee brothers medical publishers. 2009, P, 162-172.

8. Saraf S. NSAIDS-An Overview. Pharma Book Syndicate. 2008, P, 1-6.

9. Martin R. Tramer, Andrew Moore R, John M. Reynolds D. Henry J. McQuay. Quantitative estimation of rare adverse events which follow a biological progression: a new model applied to chronic NSAID use. Pain, 2000; 85:169-182.

10. Francesco G, Timothy D. Warner. Ex vivo assay to determine the cyclooxygenase selectivity of non-steroidal antiinflammatory drugs. British Journal of Pharmacology. 1999; 126:1824-1830.

11. David L. Simmons. What makes a good anti-inflammatory drug target? DDT, 2006; 11(5/6):210-219.

12. Taranalli A.D, Bhat A.R, Srinivas S, Saravanan E. Antiinflammatory, Analgesic and Antipyretic activity of certain thiazolidinones. Indian J. Pharm. Sci, 2008, 70(2), 159-164.

13. Muthanna Saud D, Fuad Al Jawad H, Adheed Sharrad K. Synthesis of Ketoprofen-L-phenylalanine and Ketoprofen- $\gamma$ aminobutyric acid ethyl esters as possible prodrugs. Irq J Pharm, 2006; 6(1):20-24.

14. Amjad Qandil M. Prodrugs of Nonsteroidal Antiinflammatory Drugs (NSAIDs), more than meets the eye: A Critical review. International Journal of Molecular Sciences, 2012, 13, 17244-17274.

15. Graham. L. Patrick. An Introduction to Medicinal Chemistry. Oxford University Press. 2011, P, 251-253.

16. Gangwar S, Giovanni M. Pauletti, Wang B, Teruna J. Siahaan, Valentino J. Stella, Ronald T. Borchardt. Prodrug strategies to enhance the intestinal absorption of peptides. DDT, 1997; 2(4):148-155.

17. Carlos E, Alberto G, Julio SR, Alejandro C. Covalent polymer-drug conjugates. Molecules, 2005; 10:114-125.

18. Roberts M.J, Bentley M.D, Harris J.M. Chemistry for peptide and protein PEGylation. Advanced Drug Delivery Reviews, 2002; 54:459-476.
19. Richard B. Greenwald, Yun H. Choe, Jeffrey McGuire, Charles D. Conover. Effective drug delivery by PEGylated drug conjugates. Advanced Drug Delivery Reviews, 2003; 55:217-250.

20. Hoste K, De Winne K, Schacht E. Polymeric prodrugs. International Journal of Pharmaceutics, 2004; 277:119-131.

21. Zacchigna M, Di Luca G, Maurich V, Boccu E. Syntheses, chemical and enzymatic stability of new poly(ethyleneglycol)-acyclovir prodrugs. IL Farmaco, 2002; 57:207-214.

22. Francesco M. Veronese, Gianfranco Pasut. PEGylation, successful approach to drug delivery. DDT, 2005; 10(21):1451-1458

23. Filpula D, Zhao H. Releasable PEGylation of proteins with customized linkers. Advanced Drug Delivery Reviews, 2008; 60:29-49.

24. Ruth Duncan. Drug-polymer conjugates: potential for improved chemotherapy. Anti-Cancer Drugs, 1992; 3:175210 .

25. Gianfranco Pasut, Mauro Sergi, Francesco M. Veronese. Anti-cancer PEG-enzymes: 30 years old, but still a current approach. Advanced Drug Delivery Reviews, 2008; 60:6978.

26. Chan Woo Lee. Drug-Release behavior of polymeric prodrugs of Ibuprofen with PEG and its derivatives as polymeric carriers. Macromolecular Research, 2004; 12(1):71-77.

27. Jaroslav Drobnik. Biodegradable soluble macromolecules as drug carriers. Advanced Drug Delivery Reviews, 1989; 3:229-245.

28. Vyas S.P, Roop K Khar. Targeted and Controlled Drug Delivery. CBS Publishers. 2008, P, 24-27.

29. Vyas S.P, Roop K Khar. Targeted and Controlled Drug Delivery. CBS Publishers. 2008, P, 114-119.

30. Anjali Nayak, Anurekha Jain. In vitro and in vivo study of poly(ethyleneglycol) conjugated ibuprofen to extend the duration of action. Sci Pharm, 2011; 79:359-373.

31. Kulkarni S. K. Hand book of Experimental Pharmacology. Vallabh Prakashan. 1999, P, 123-128.

32. Mohammad Hayatul Islam, Iffat Zareen Ahmad, Mohammad Tariq Salman. In vivo Evaluation of Anti-inflammatory and Analgesic activities of Nigella sativa seed during germination. International Journal of Pharmacy and Pharmaceutical Sciences, 2013; 5(4):451-454.

33. Rajagoundan Rajavel, Thangavel Sivakumar, Murugesan Jagadeeswaran, Perumal Malliga. Evaluation of analgesic and anti-inflammatory activities of Oscillatoria willei in experimental animal models. Journal of Medicinal Plants Research, 2009; 3(7):533-537.

34. Zulfiker AHM, Mahbubur Rahman M, Kamal Hossain M, Mazumder MEH, Sohel Rana M. In vivo analgesic activity of ethanolic extracts of two medicinal plants- Scoparia dulcis L. and Ficus racemosa Linn. Biology and Medicine, 2010; 2(2):42-48.

35. Kulkarni S.K. Hand book of Experimental Pharmacology. Vallabh Prakashan. 1999, P, 128-130. 